\title{
A Study of Intelligent Information Processing in Human Resource Management in China
}

\author{
Li Zhang and Lunqu Yuan \\ School of Economics and Management, Beijing Jiaotong University, Beijing 100044, P.R. \\ China lzhang@bjtu.edu.cn lqvuan@bjtu.edu.cn
}

\begin{abstract}
More and more HRM systems today are being changed to e-HRM systems in China. This is mainly due to the advent of Internet technology and the emerging concept of business intelligence. This study shows the evolution of information systems and information processing in the HRM domain and provides an implementation case in a large Chinese state-run enterprise. The experiences and lessons learned from this case reveal several common problems in developing information systems in the HRM domain.
\end{abstract}

Keywords: Chinese enterprise, Intelligent information processing, E-HRM,

\section{INTRODUCTION}

The advent of information technology (IT) and information systems, together with Internet technology, has inspired many changes in today's business world [1,2]. The impact of IT on today's business is obvious in at least two categories: (1) the improvement of business in efficiency, effectiveness and productivity; (2) the transition of business in the way people create, organize, manage and operate an enterprise. This study shows how information systems and IT are being used in human resource management (HRM) domains through an implementation case in a Chinese enterprise. The experiences and lessons learned from this case reveal several common problems in developing information systems in the HRM domain. HRM practices have a long history. Before the mid-1980s, most practices had focused on the low level, routine tasks such as recruiting, record-keeping, rewards and wages [3]. It is believed that Fombrun et al. pioneered the development of the concept of strategic HRM and started linking HRM functions with the organizational overall strategy [4]. Strategic HRM mainly focuses on activities involving HR planning and $\mathrm{HR}$ policies such as internal career opportunities, training systems, performance appraisals, profit-sharing plans, employment security, voice mechanisms, participation in decision-making, and the degree to which jobs are defined $[3,5]$. Strategic HRM perceives people as critical organizational investments, strategic resources and competitive advantages which determine the success and failure of an organization $[6,7,8,9]$. Therefore, HRM has gone through the transition from taskoriented HRM to people-oriented strategic HRM. As one of the driving factors that help today's business transit, IT inevitably should play an important role in the HRM domain [10].

Please use the following format when citing this chapter:

Zhang. L.. Yuan, L., 2007, in IIIP International Federation for Information Processing, Volume 254. Research and Practical Issues of Enterprise Information Systems II Volume 1, eds. L. Xu. Tjoa A., Chaudhry S. (Boston: Springer), pn. 493-502 
Information systems have been applied to HRM for decades. However, the way of using information systems and the way of processing information for HRM have evolved, and dramatically improved, over the last decade. This is mainly due to the advent of Internet technology and the emerging concept of business intelligence. In the mid-1990s, the Internet cracked into business operations and the concept of ebusiness was born. Using Internet technology or IT in general to run business functions, including HRM, is widely accepted as electronic business (e-business). Correspondingly, using IT in HRM is called e-HRM. Dave Ulrich [11] is one of many early e-HRM advocates. Straus et al. researched several impacts of Internet technologies on managing human resources and concluded that the "advances in communication technologies and organizational form suggest the re-evaluation of traditional personnel practices" $[10,11]$. Although the literature has explored the opportunities provided by IT to dramatically transform organizations and to help organizations in gaining competitive advantages [12-13], Powell and Dent-Micallef [14] argued that IT alone has not produced competitive advantages, but using IT to leverage intangible, complementary human and business resources has helped organizations gain competitive advantages [12-14]. The proper application of IT in HRM has been proved to be a successful way of running today's business.

\section{THE CURRENT STATUS OF E-HRM AND EXISTING PROBLEMS IN CHINA}

\subsection{The Current Status}

Using the customer database of www.chinahr.com, www.ehr4u.com has done research on the current situation of Chinese enterprise's e-HRM over the past days. This research collected 2005 questionnaires from various enterprises in China, 1775 of which were valid. Among all the enterprises surveyed, Chinese domestic enterprises accounted for $78.37 \%$ and foreign invested companies took up the remaining $21.63 \%$.

The research showed that even though most enterprises in China take a positive attitude towards e-HRM using computers, networking, business intelligence and Internet technology, they are just taking the first step in revolutionizing HRM with IT. Over $70 \%$ of them have not introduced any HRM systems. Most HR managers do not possess sufficient knowledge in IT and information systems to help them in using eHRM systems. The study showed that over half of the HR managers surveyed have a mediocre ability in applying IT, among whom those from enterprises without use of HRM systems perform worse in applying IT $(58 \%$ answered levels of poor and very poor, which means that they are just able to use office software and to get information from the Internet). $55 \%$ of the managers from enterprises that have used HRM systems, however, have above-average ability in applying IT.

Another result from this study showed the levels of communication and cooperation between the IT department and the HR department. Enterprises preparing 
to use HRM systems are facing more problems of cooperation between IT and HR departments than those that have adopted HRM systems. Our case study shows that it is quite common that two departments play buck-passing to relieve themselves of responsibilities. In general, most enterprises face a certain level of problems in communications and cooperation between the IT department and the HR department. The results also showed that $71 \%$ of enterprises have not used HRM systems. Most of them are enterprises with a size of less than 500 employees and enterprises of this type are in more urgent need of using HRM systems. The research showed that $55 \%$ of the enterprises have used HRM systems for less than two years while those who have used it for over two years only account for $29 \%$. Thus Chinese enterprises' efforts in revolutionizing HRM with IT did not start until two years ago.

In today's HRM systems market of mainland China, no prominent HRM systems suppliers or brands have emerged. In terms of market share, no one has more than $10 \%$. Enterprises that develop their own systems take up a share as big as $38.2 \%$, and other unnamed brands account for another $24.3 \%$. HRM systems products manufactured by Chinese enterprise resource planning (ERP) enterprises have not fully grown. HRM systems manufactured by foreign ERP enterprises are restrained in market share due to factors such as price and localization. Professional HRM systems suppliers in China are still in their infancy and most of them are still able to establish complete HRM systems solutions and remain generic software developers.

\subsection{Existing Problems}

Several major problems exist in today's Chinese enterprises that may hamper the process of adopting e-HRM. We summarize them in the following four categories.

1. There is a misperception of e-HRM from top management. Many VIPs regard HRM as a kind of unavoidable cost instead of realizing the importance of HRM for the development of enterprises; nor do they have sufficient understanding of in-depth questions such as how to carry out e-HRM, what problems they may encounter in this process and what value it may bring to the enterprise. In addition, they have various misunderstandings about e-HRM.

2. There is an unbalanced development in enterprises' digitization which predetermines whether e-HRM can be carried out successfully. Many enterprises either spend too much on e-HRM development or repeat what they already have and waste money. When undertaking e-HRM, enterprises should carefully evaluate what they have already developed, e.g. the computer systems, network systems, and other business applications such as accounting and finance, sales and marketing, manufacturing, and HRM. When choosing e-HRM systems, enterprises should choose those which fit their current organization and satisfy their organizational demands.

3. HRM systems or e-HRM in Chinese enterprises are still in their infancy stage. There are three important parts in e-HRM development: (1) electronic data management; (2) procedural management; (3) strategic management. At present, the strategic functions of e-HRM software such as HR planning, personnel professional development planning and core capability management are still not being emphasized in many Chinese enterprises. 
4. There is a lack of competent staff. In the e-HRM development process, HRM knowledge must be organically integrated with IT. However, most enterprises do not have sufficient staffs that possess both HRM and IT knowledge. Those who are experts in HRM have little knowledge about IT techniques and those who know IT do not know HRM well, have little managerial experience and do not have adequate knowledge about the needs of HR businesses. Meanwhile, many managers are not ready to enter the information age. They are short of decent skills in computer operation, Internet applications and information systems usage. Therefore, e-HRM has become a burden for them.

\section{A CASE STUDY OF AN ENTERPRISE E-HRM SYSTEM IN CHINA}

\subsection{Brief Introduction to Plant A}

With a history of nearly 70 years, Plant $\mathrm{A}$ is a large state-owned enterprise in China. It is one of the top 500 industrial enterprises in China, and is the major researching and manufacturing center of electronic track towing equipment in China. Plant A primarily researches, manufactures and sells high-speed electronic locomotives, metro trains, light-rail trains and electric rail trains, with an annual output of 300 mainline electric locomotives. Plant A owns the biggest workshop for final assembly of electric locomotives and modernized manufacturing centers of locomotive veering shelves, high power electric towing machinery, towing and electric transformers, and resin grit foundry production lines. It owns large quantities of advanced equipment such as high-precision numerically controlled processing centers, robot welders, and numerically controlled cutting, punching, folding and pressing machine tools. Plant A currently has over 10,000 employees, and nearly 3000 of these are engaged in research and development.

\subsection{The Overall Demand of Plant A for an E-HRM System}

The strategic transformation and rapid development in Plant A caused a managerial revolution in many aspects. Starting from innovation and revolution in HRM, and further infiltrating into marketing, financing, manufacturing and researching, Plant $\mathrm{A}$ has found the best way to gain an upper hand in competition via managerial innovation. Facing the situation of Plant $\mathrm{A}$, an HRM consulting team has decided that its consulting objective is regrouping HR to improve performance. In early January of 2002 , after a systematic investigation and a lengthy communication with Plant $A$, the consulting team figured out that an e-HRM system for Plant $\mathrm{A}$ has the following specific demands.

1. The system must normalize the HRM system and make HRM more intelligent, networked and knowledge-driven, using e-HRM to make the enterprise's HRM dynamically controllable, which includes overall control, dynamic control and proper personnel-position matching. 
2. The e-HRM system must cover all aspects of HRM. It should achieve the automation of HRM operations, the normalization of HRM procedures and the systematization of the management, making the e-HRM system become a platform for an informational and professional enterprise's HRM. The HRM department should become an organic entity to make communication smooth and feedback prompt.

3. The system must update old concepts via the execution of the e-HRM program and build up a proper enterprise culture. The enterprise culture includes giving employees who contribute the most the economic benefits they deserve, and then fulfilling the principle of getting paid according to contribution.

4. It must perfect the management system and form a specific set of rules and regulations, contracts of labor and other related regulations (security and privacy policies, attendance records etc.) via execution of the e-HRM program.

5. The e-HRM system should be as advanced, complete, practical, efficient, flexible, open and automatic as possible. It should also be easy to operate, maintain and expand, be fault-tolerant, be safe and reliable and be able to handle and coordinate different events at the same time. It should have a strict multiple-user authorization management and functions such as database visiting, data copying, operation and visiting $\log$ records and system restoration.

6. The e-HRM system should be developed by using mainstream instruments. It should be ensured that it is open, flexible and stable. The system should be based on the browser/server structure, using a uniform platform with a simple and friendly interface. The database should be structured properly, be easy to maintain and be safe (using databases such as MS SQL DB2 or Oracle). At the same time, the system should have a qualified data interface and be compatible with various kinds of databases. The interface should allow the HRM system to seamlessly connect to the ERP system, financial system, office automation system and attendance records system, and to conveniently transmit historical data, such as Excel documents, into the database. It should guarantee the smooth data flow in the system (changes to the data in the attendance records system

\subsection{Solutions and the Implementation}

After a complete investigation and analysis, the consulting team and Plant $\mathrm{A}$ were ready to find some solutions for the plant's HRM. In March 2002, in line with the solution to Plant A's HRM, the consulting team began to implement the e-HRM system.

\subsubsection{The General Criteria}

1. Put forward the managerial principle to enable the managers to grasp the essence of HRM.

2. Carry out goal management to scout and control the whole process and enable each department/each position to reach its set goal. 
3. Optimize managerial procedures to ensure the shortest procedure, the strongest functions, the lowest cost and simplicity of operation. This also makes each job go smoothly according to the procedures.

4. Regulations should be clear, reasonable, scientific and applicable and ensure normalized HRM.

5. Develop software modules out of normalized managerial procedures.

\subsubsection{Implementation Model}

\section{Step 1 HRM}

-HR diagnosis

-Design medium and long-term strategic system for HRM

-Assess and design wage and stimulation system

-Stipulate functions for top officials of the enterprise

-Design talent recruitment and selection process

-Design performance assessment system

-Direct job duty arrangements and job analysis

-Provide an HRM policy system

Step 2 Organizational transformation and structural regrouping

-Diagnose organizational behavior

-Solve disputes between organizational structures and the enterprise's developing strategies

-Set up an authority distribution system

-Optimize organizational structures and managerial procedures

-Organize cultural construction and forge organizational concepts

-Establish academic organizations

Step 3 Enterprise training and course designs

-Analyze on training needs and design training courses

-Share cases interactively

-Design an in-enterprise training system and procedures

-Establish a sophisticated training assessment system

Step 4 Provide user instructions and collect feedback for future maintenance

Plant A completed the construction of the e-HRM system by the end of 2002. The system has been running well.

\subsubsection{Value Analysis}

Value 1 The e-HRM system makes it easier for Plant A to strengthen its internal cooperation. Along with the principle of new hired loyalty, a noteworthy phenomenon is that the relationship between the staff and managers as well as that between managers and the teams are gradually becoming the crucial factor in determining whether they are willing to stay in the team.

From a daily perspective, the personnel mainly deal with the teams they belong to rather than the enterprise. Strengthening communications between the personnel and their supervisors adds to the sense of their belonging to the enterprise. The e-HRM 
system provides a platform for prompt communication, and makes a seamless cooperation relationship among the personnel come true through management, electronic magazines and e-mails. The system's personnel self-help terminals and managers' self-help terminals provide horizontal and vertical communication tools.

Value 2 The e-HRM system paves the way for the enrichment of an enterprise culture and a healthy development of Plant A. The enterprise culture of Plant A comes with the enterprise itself. It is based on the dominating fundamental values, consisting of its exterior expressions such as personnel behavior, management style and management policy.

By applying the e-HRM system and introducing the HRM consultation service, Plant A further carries out its enterprise culture and works on a unitary value. The eHRM system has helped Plant A establish a new working approach of creative thinking, circumventing traditions and seeking innovation and a new system of rewards and stimulation.

Value 3 The e-HRM system brings down Plant A's management costs and raises its productivity. The great functions of an e-HRM system in procedure control and quantified management can be used to ensure that HRM follows a pattern of people first in real terms. Networking computers is an effective means to achieve procedure control. For example, software is used to complete the whole process of a recruitment plan, from drawing the plan, choosing the recruiting channel, and setting it into motion by selecting applicants, giving interviews and undertaking assessments, to making decisions and calculating costs. From an information management perspective, the e-HRM system collects, processes, analyzes and disseminates information for the whole enterprise. Compared to manual work, it makes the procedure more normative, more effective and more accurate. . Plant A's increase in efficiency after the application of the e-HRM system is mainly reflected in the following aspects: (1) It takes less time to make replies; (2) Traveling cost is reduced. Recruitment, training and assessments are all done online which eliminates a huge amount of traveling cost;(3) It takes less time for decisions to be put into action.; (4) Since there are personnel self-help service platforms, most of the trivial personnel affairs can be processed online.

\section{THE FUTURE TRENDS OF E-HRM IN CHINA}

There are four areas that appear to be popular in China for future e-HRM development.

\subsection{Digitization}

Over the last decade, people have experienced a lot of e-terms such as ecommerce, e-business, e-government, e-manufacturing, e-procurement, e-learning and e-HRM. It is true that more and more organizations or enterprises have started using IT to run their businesses. China is one of the fastest growing countries in the world, and digitization has been a major topic in most Chinese enterprises $[15,16]$. The first step of an e-HRM strategy is office digitalization. It uses computer technology to 
handle office work which mainly includes the making, transporting and stocking of documents and materials. Office automation is spreading more and more widely, paving the way for e-HRM development. A computer network-connected environment is highly needed by e-HRM.

\subsection{More Information Systems to be Developed and Used}

Various types of information systems provide a means of collecting, processing, storing, analyzing and applying information to meet various demands from enterprises. By using information systems, we can optimize the current managerial and organizational structures and adjust managerial mechanisms. The coordination between different departments can be strengthened through information systems. Efficiency and effectiveness will be improved for decision-making processes since the required information can be provided to decision-makers in a more timely manner and more accurately. Information systems in e-HRM can help us achieve an integrated management covering various aspects such as personnel affairs, wages, statistics, report forms, documents, securities, contracts and authority approval. They provide a seamless connection between different business departments, avoid duplicate data collection and ensure consistency and accuracy of data. They provide valuable information in a comprehensive, accurate and prompt way, fully and effectively satisfying the needs of HRM activities.

\subsection{E-HRM Becomes a Solution for HRM}

IT infrastructure is upgraded year after year. Hardware platforms have experienced different forms over the past several decades, from independent computers and networked computers to the client/server architecture and the Internet. Most enterprises today have started using the Internet in their business operations, ranging from the most fundamental Internet service such as getting business information and news and providing enterprise information, to more advanced applications such as online transactions and online services. The concept of e-HRM was born in such a business environment. e-HRM promotes the comprehensive development of HRM and emphasizes an organic binding of information with HR development. Its functions include HR development; talent forecasting; decision-making support by providing precise HR data and analytical reports to decision-makers; performance assessment; and online recruitment and professional training.

\subsection{More Qualified E-HRM Users are Need}

The HRM personnel are the main body of HRM information and a qualified and professional HRM team is a guarantee of its success. The high quality of HRM personnel means that the HRM personnel must possess the most current and advanced knowledge. They must build and strengthen information awareness, learn the information management concept, and gain the skills in using information systems, Internet technology and applications. They also need to know the new content and the 
new requirement of HRM in today's information age. Instead of only doing daily routines, e-HRM needs to provide information and analysis of HR data at a strategic level of the enterprise and help top management make decisions for the whole enterprise. Such an intelligent system requires intelligent users. It is the key of successful e-HRM.

\section{CONCLUSIONS}

The advent of the knowledge economy and widespread application of computer technology and the Internet require today's enterprise management to be digitized. This digitization in turn requires HRM to be changed. E-HRM is born in such an environment. Through the analysis of the current status of HRM in Chinese enterprises and through a case study, we show why e-HRM is needed and how eHRM is developed. We hope the experiences and the lessons we learned in this case will help people in developing their own e-HRM systems. E-HRM in China is still in its infancy. Many enterprises, particularly small and medium-sized ones, have not accepted the concept of information and have not undertaken any sort of construction of it. On the other hand, some large enterprises set out blindly to develop their e-HRM systems without really knowing what e-HRM is and how to develop it. They just follow the fashion which only backfires on them. This study has shown how to prepare the enterprises themselves to start an e-HRM project and do it successfully.

\section{REFERENCES}

1. L. Xu, The contribution of systems science to information systems research, Systems Research and Behavioral Science. Volume 17, Number 2, pp.105-116, (2000).

2. L. Xu, C. Wang, X. Luo, and Z. Shi, Integrating knowledge management and ERP in enterprise information systems, Systems Research and Behavioral Science. Number 23, pp.147-156, (2006).

3. J. Storey, Developments in the Management of Human Resources (Blackwell: London, 1992).

4. C.J. Fombrun, N.M. Tichy, and M.A. Devanna, Strategic Human Resource Management (Wiley: New York, 1984).

5. J.A. Sonnenfeld and M.A. Peiperl, Staffing policy as a strategic response: a typology of career system, Academy of Management Review. Volume 13, pp.588-600, (1988).

6. J. Barney, Firm resources and sustained competitive advantage, Journal of Management. Volume 17, pp.99-120, (1991).

7. D. Ulrich, HR of the future: conclusions and observations, Human Resource Management. Volume 36, Number 1, pp.175-179, (1997).

8. J. Pfeffer, The Human Equation: Building Profits by Putting People First (Harvard Business School Press: Boston, MA, 1998).

9. B.E. Becker, M.A. Huselid, and D. Ulrich, The HR Scorecard: Linking People, Strategy and Performance (Harvard Business School Press: Boston, MA, 2001).

10. S.G. Straus, S.P.Weisband, and J.M. Wilson, Human resource management practices in the networked organization: impacts of electronic communication systems, Trends in Organizational Behavior. Volume 5, eds. C.L. Cooper and D.M. Rousseau (Wiley: New York, pp.127-154, 1998). 


\section{Li Zhang and Lunqu Yuan}

11. D. Ulrich, From e-Business to e-HR, Human Resource Planning. Volume 23, Number 2, pp.12-21, (2000).

12. M.J. Culnan and M.L. Markus, Information technologies, in History of Organizational Communication, eds. F.M. Jablin, L.L. Putman, K.H. Roberts and L.W. Porter (Newbury Park, CA: Sage, 1987), pp.420-443.

13. G.P. Huber, A theory of the effects of advanced information technologies on organizational design, intelligence, and decision-making, Academy of Management Review. Volume 15, pp.47-71, (1990).

14. T.C. Powell and A. Dent-Micallef, Information technology as competitive advantage: the role of human, business, and technology resources, Strategic Management Journal. Volume 18, Number 5, pp.375-405, (1997).

15. C. Wang and $\mathrm{L}$. $\mathrm{Xu}, \mathrm{ERP}$ research, development and implementation in China: an overview, International Journal of Production Research. Volume 43, Number 18, pp.3915-3932, (2005).

16. S. Guo, C. Wang, and X. Luo, A study on knowledge management in enterprise information systems, in Research and Practical Issues of Enterprise Information Systems (2006).

17. L. Zhang, S. Guo, Y. Liu, and J. Choi, Study of systems methodology in ERP implementation in China, in Research and Practical Issues of Enterprise Information Systems, International Federation for Information Processing, Volume 205, eds. A. Tjoa, L. Xu and S. Chaudhry (Springer: Boston, MA, 2006), pp.665-666. 